\title{
PENGARUH PEMASANGAN MODEL TIANG BERBAHAN BAMBU KUNING DI HILIR PINTU AIR TERHADAP ENERGI SPESIFIK
}

\author{
Agnes Rafelia, I Made Kamiana ${ }^{2}$ dan Dwi Anung Nindito ${ }^{3}$ \\ ${ }^{123}$ Program Studi Teknik Sipil, Fakultas Teknik, Universitas Palangka Raya \\ E-mail: agnesrafelia1996@gmail.com ${ }^{1}$, kamianamade@eng.upr.ac.id ${ }^{2}$,dan \\ dwi anungnindito@eng.upr.ac.id ${ }^{3} /$ HP.+6281348245229 1
}

\begin{abstract}
ABSTRAK
Energi spesifik loncatan hidraulik yang terjadi di hilir pintu air menjadi salah satu faktor penyebab gerusan di saluran. Penelitian ini bertujuan untuk mengetahui formasi model tiang di hilir pintu air yang paling signifikan berpengaruh terhadap energi spesifik. Penelitian ini dilakukan pada flume kaca dengan panjang $6 \mathrm{~m}$; lebar 0,2 m; dan tinggi 0,40 m. Dasar flume dilapisi kayu. Model tiang dibuat dari bambu kuning yang diraut. Diameter model tiang $0,2 \mathrm{~cm}$. Tinggi model tiang 7 $\mathrm{cm}$ dan $12 \mathrm{~cm}$. Pola model tiang adalah paralel. Pemasangan model tiang di hilir pintu air dilakukan dalam delapan formasi. Debit yang dialirkan ke flume yaitu $0,00774 \mathrm{~m}^{3} / \mathrm{dt}$ dan $0,00191 \mathrm{~m}^{3} / \mathrm{dt}$. Pengukuran kedalaman aliran dilakukan pada 16 titik, yaitu di titik pintu air, dan di titik-titik lainnya yang tersebar di hulu formasi model tiang, di tengah formasi model tiang, dan di hilir formasi model tiang. Hasil penelitian menunjukkan, formasi model tiang di hilir pintu air dapat memperbesar energi spesifik. Formasi model tiang yang paling signifikan berpengaruh terhadap energi spesifik adalah formasi dengan pola paralel penuh, tinggi model tiang $12 \mathrm{~cm}$ atau 3/10 dari tinggi flume, dan jarak antar model tiang 1/8 dari lebar flume.
\end{abstract}

Kata kunci: energi spesifik, formasi tiang, hilir pintu air

\section{ABSTRACT}

The specific energy of the hydraulic jump that occurs downstream of the floodgate is one of the factors causing scouring in the channel. This study aims to determine the pile model formation at the downstream of the floodgate which has the most significant effect on specific energy.This research was conducted on a glass flume with a length of $6 \mathrm{~m} ; 0.2 \mathrm{~m}$ wide; and a height of $0.40 \mathrm{~m}$. The base of the flume is covered with wood. The pole model is made of crocheted Bambusa vulgaris. Pole model diameter of $0.2 \mathrm{~cm}$. Pole model height is $7 \mathrm{~cm}$ and $12 \mathrm{~cm}$. The pattern of the pile model is parallel. Installation of the pole model downstream of the floodgate is carried out in eight formations. The discharge flowed to the flume is $0.00774 \mathrm{~m}^{3} / \mathrm{s}$ and $0.00191 \mathrm{~m}^{3} / \mathrm{s}$. Flow depth measurements are carried out at 16 points, namely at the floodgate point, at the upstream of the pile model formation, in the middle of the pile model formation, and downstream at the pile model formation. The results showed, the pile model formation at the downstream of the floodgate can reduce specific energy. The pile model formation that has the most significant effect on specific energy is the formation with a fully parallel pattern, the height of the pile model is $12 \mathrm{~cm}$ or 3/10 of the flume height, and the distance between the pile models is 1/8 of the flume width.

Key words: specific energy, pole formation, downstream of the floodgates 


\section{PENDAHULUAN}

Aliran melalui bawah pintu air tergolong aliran melalui penyempitan tampang aliran (Chow, 1989). Setelah melalui bawah pintu air, aliran dapat dalam keadaan bebas atau tenggelam (Kamiana, 2018). Dalam keadaan aliran bebas, aliran umumnya akan diawali dengan aliran super kritis dan diakhiri dengan aliran sub kritis. Diantara dua jenis aliran tersebut terjadi loncatan hidraulik (Anggrahaini, 1997).

Apabila energi spesifik sangat besar pada awal loncatan hidraulik maka dapat menimbulkan gerusan pada saluran (Aji dan Maraden, 2008). Energi spesifik yang besar tersebut perlu diredam, misalnya dengan pemasangan sekat ambang datar, blok penghalang aliran atau baffle blocks (Adipura, 2013; Aji dan Maraden, 2008; Bahar dan Ruzardi, 2019).

Adipura (2013) menyatakan bahwa pemasangan kolam olak tipe solid roller bucket dan baffle blocks dapat meredam energi loncatan hidraulik. Aji dan Maraden (2008) menyatakan bahwa pemasangan sekat ambang datar pada lantai kolam olak efektif meredam energi spesifik loncatan hidraulik.

Sejalan dengan yang dinyatakan oleh Adipura (2013) maupun Aji dan Maraden (2008), Nenny dan Imran (2018) maupun Bahar dan Ruzardi (2019) juga menyatakan bahwa pemasangan baffle blocks pada kolam olak efektif meredam energi spesifik loncatan hidraulik.

Sementara itu, Wulandari (2020) menyatakan bahwa pemasangan formasi model tiang dengan pola zig-zag di hilir pintu air mampu meninggikan kedalaman aliran sehingga tidak terjadi loncatan hidraulik, dan mampu merubah karaktersistik aliran pada titik-titik tinjauan dari superkritis menjadi subkritis.

Memperhatikan uraian di atas, maka dalam penelitian ini dicoba dilakukan peredaman energi spesifik loncatan hidraulik di hilir pintu air dengan cara memasang formasi model tiang berbahan bambu kuning dengan pola paralel.

\section{Tujuan Penelitian}

Tujuan dari penelitian ini adalah untuk mengetahui pengaruh pemasangan formasi model tiang dan tanpa formasi model tiang di hilir pintu air terhadap energi spesifik.

\section{METODE PENELITIAN}

\section{Tempat Penelitian}

Penelitian ini dilakukan di Laboratorium Hidrologi dan Hidrolika, Jurusan Teknik Sipil, Fakultas Teknik, Universitas Palangka Raya.

\section{Peralatan, Bahan, dan Formasi Model}

Penelitian ini menggunakan flume prismatik dengan dimensi $6 \times 0,2 \times 0,40 \mathrm{~m}$. Dinding flume dibuat dari kaca. Dasar flume dibuat dari kayu dengan dimensi $4 \mathrm{x}$ 
$0,19 \times 0,04 \mathrm{~m}$. Model tiang dibuat dari bambu kuning yang diraut. Diameter model tiang $0,2 \mathrm{~cm}$. Variasi tinggi model tiang adalah $\mathrm{t}=7 \mathrm{~cm}$ dan $\mathrm{t}=12 \mathrm{~cm}$. Pemasangan formasi model tiang dilakukan dengan pola paralel (Gambar 1). Jumlah formasi model tiang sebanyak 8 formasi, yaitu: (i) formasi paralel penuh $\mathrm{t}=7 \mathrm{~cm}$, (ii) formasi paralel $1 / 2$ hulu $\mathrm{t}=7 \mathrm{~cm}$, (iii) formasi paralel $1 / 2$ hilir $\mathrm{t}=7 \mathrm{~cm}$, (iv) formasi paralel penuh $\mathrm{t}=12 \mathrm{~cm}$, (v) formasi paralel $1 / 2$ hulu $\mathrm{t}=12 \mathrm{~cm}$, (vi) formasi paralel $1 / 2$ hilir $\mathrm{t}=12 \mathrm{~cm}$, (vii) formasi paralel kombinasi $1 \mathrm{t}=7 \mathrm{~cm}$ dan $\mathrm{t}=12$ $\mathrm{cm}$, (viii) formasi paralel kombinasi $2 \mathrm{t}=12 \mathrm{~cm}$ dan $\mathrm{t}=7 \mathrm{~cm}$.
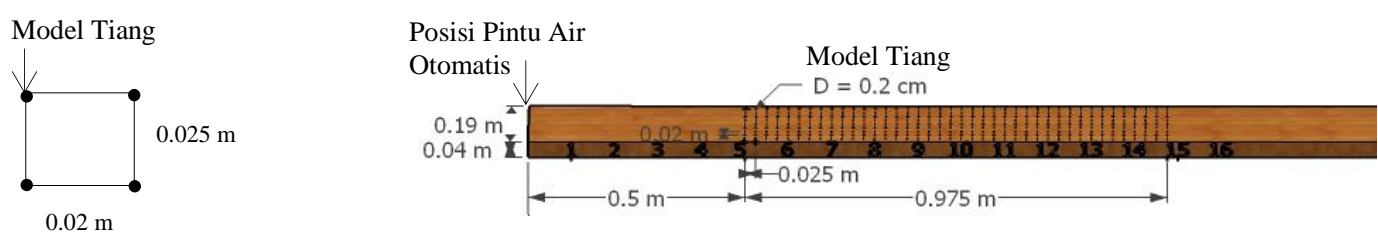

Gambar 1. Formasi model tiang paralel di hilir pintu air dengan jarak antar model tiang 1/8 dari lebar flume

\section{Pengumpulan dan Analisis Data}

Pengumpulan dan analisis data dilakukan dengan cara sebagai berikut:

1. Pada setiap formasi model tiang yang dipasang di hilir pintu air, dialirkan dua variasi yaitu $\mathrm{Q}_{1}=0.00191 \mathrm{~m}^{3} / \mathrm{dt}$ dan $\mathrm{Q}_{2}=0.00774 \mathrm{~m}^{3} / \mathrm{dt}$.

2. Parameter yang diukur pada setiap variasi debit dan pada setiap formasi model tiang adalah kedalaman aliran atau y (m). Pengukuran kedalaman aliran dilakukan dengan point gauge.

3. Parameter yang dihitung adalah kecepatan aliran rata-rata penampang (V). Rumus yang digunakan:

$\mathrm{v}=\frac{\mathrm{Q}}{\mathrm{A}}$

dengan:

$\mathrm{V}$ : kecepatan aliran rata-rata penampang $(\mathrm{m} / \mathrm{dt})$

$\mathrm{Q}: \operatorname{debit}\left(\mathrm{m}^{3} / \mathrm{dt}\right)$

A : luas penampang basah flume $\left(\mathrm{m}^{2}\right)$

4. Energi spesifik pada tiap-tiap titik pengukuran dihitung dengan rumus:

$\mathrm{E}=\mathrm{h}+\frac{\mathrm{V}^{2}}{2 \mathrm{~g}}$

dengan:

E : energi spesifik (m)

$\mathrm{h}$ : kedalaman aliran atau energi potensial (m)

$\frac{\mathrm{v}^{2}}{2 \mathrm{~g}}$ : energi kinetik $(\mathrm{m})$

\section{HASIL \& PEMBAHASAN}

\section{Energi Spesifik Tanpa Formasi Model Tiang}

Profil energi spesifik di hilir pintu air pada kondisi tanpa formasi model tiang disajikan dalam bentuk grafik (lihat Gambar 2). Grafik ini menunjukkan besarnya energi spesifik pada tiap-tiap titik pengukuran dengan debit $\mathrm{Q}_{1}$ dan $\mathrm{Q}_{2}$. Jumlah titik pengukuran 16 titik. 


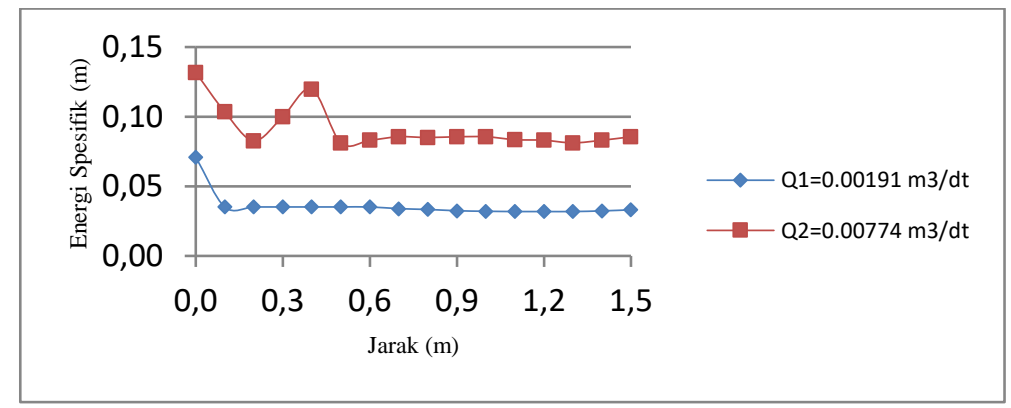

Gambar 2. Profil energi spesifik di hilir pintu air pada kondisi tanpa formasi model tiang

Berdasarkan Gambar 2, pada aliran dengan debit $\mathrm{Q}_{1}$, dapat dilihat bahwa dari titik dengan jarak $0 \mathrm{~m}$ ke titik pengukuran berikutnya sampai dengan titik dengan jarak 1,5 m dari pintu air, energi spesifik semakin menurun. Sementara itu, pada aliran dengan debit $\mathrm{Q}_{2}$, dapat dilihat bahwa dari titik dengan jarak $0,2 \mathrm{~m}$ ke titik pengukuran berikutnya sampai dengan jarak 0,4 m energi spesifik meningkat, kemudian energi spesifik menurun sampai ke titik dengan jarak 1,5 $\mathrm{m}$ dari pintu air.

Berdasarkan Gambar 2 juga dapat dilihat bahwa pada tiap-tiap titik pengukuran, energi spesifik dengan debit $\mathrm{Q}_{2}$ lebih besar dari energi spesifik dengan debit $\mathrm{Q}_{1}$. Pada pengaliran dengan debit $\mathrm{Q}_{2}$ energi spesifik maksimum sebesar 0,132 $\mathrm{m}$ yang terjadi pada jarak $0 \mathrm{~m}$ dari pintu air, dan energi spesifik minimum sebesar $0,081 \mathrm{~m}$ pada jarak $0,5 \mathrm{~m}$ dan $1,3 \mathrm{~m}$ dari pintu air. Pada pengaliran dengan debit $\mathrm{Q}_{1}$ energi spesifik maksimum sebesar 0,071 $\mathrm{m}$ yang terjadi pada jarak $0 \mathrm{~m}$ dari pintu air, dan energi spesifik minimum sebesar $0,032 \mathrm{~m}$ pada jarak 0,9 sampai $1,4 \mathrm{~m}$ dari pintu air.

\section{Energi Spesifik Akibat Formasi Model Tiang}

Profil energi spesifik di hilir pintu air akibat pemasangan formasi model tiang di hilir pintu air, disajikan mulai dari Gambar 4 sampai dengan Gambar 11. Gambargambar tersebut secara umum menunjukkan energi spesifik pada tiap-tiap titik pengukuran di hilir pintu air dengan debit $\mathrm{Q}_{1}$ dan $\mathrm{Q}_{2}$.

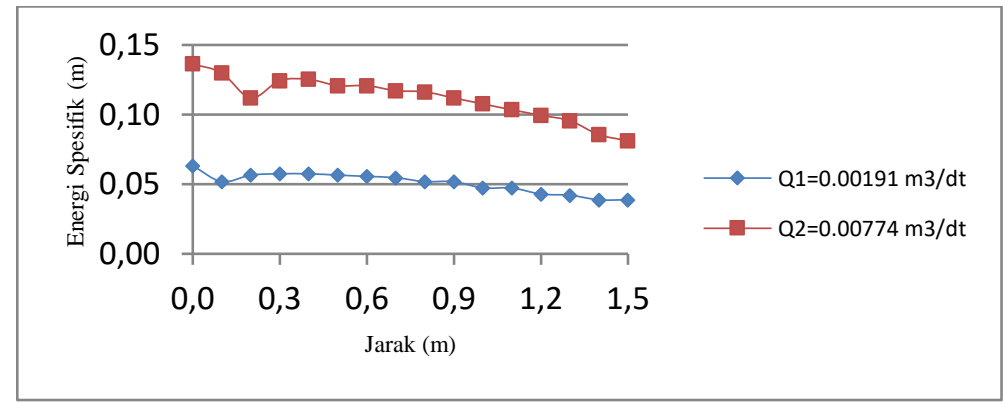

Gambar 4. Profil energi spesifik di hilir pintu air pada formasi paralel penuh $\mathrm{t}=7 \mathrm{~cm}$ 


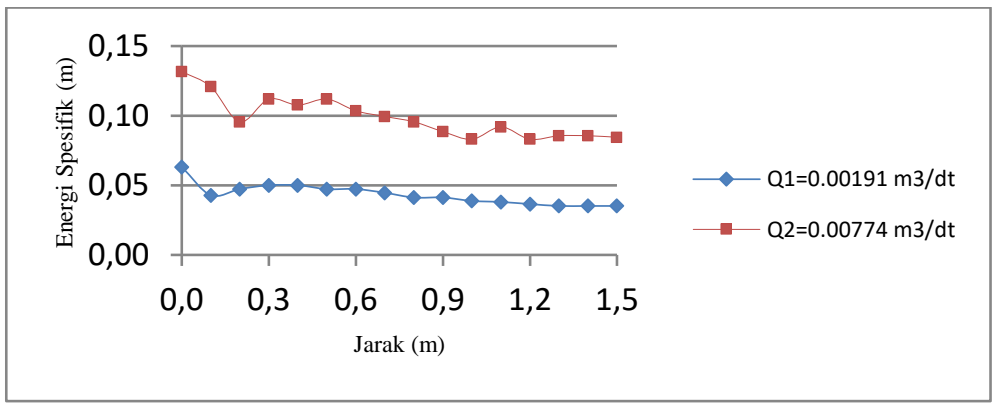

Gambar 5. Profil energi spesifik di hilir pintu air pada formasi paralel $1 / 2$ hulu $\mathrm{t}=7 \mathrm{~cm}$

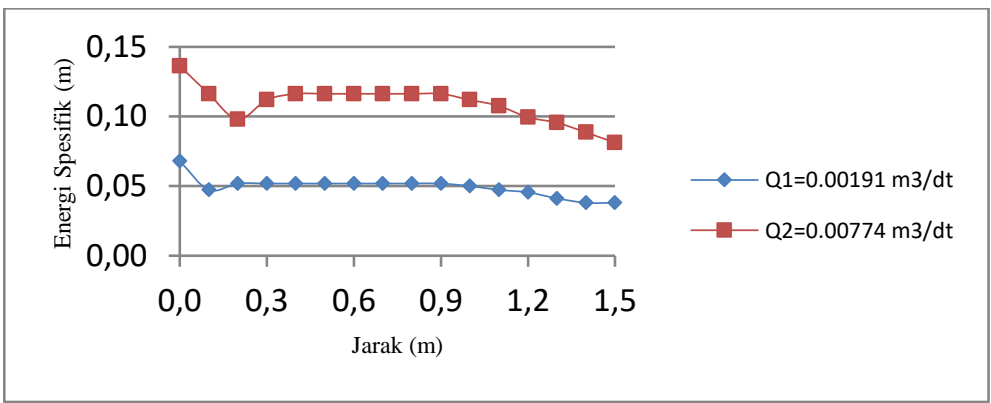

Gambar 6. Profil energi spesifik di hilir pintu air pada formasi paralel $1 / 2$ hilir $\mathrm{t}=7 \mathrm{~cm}$

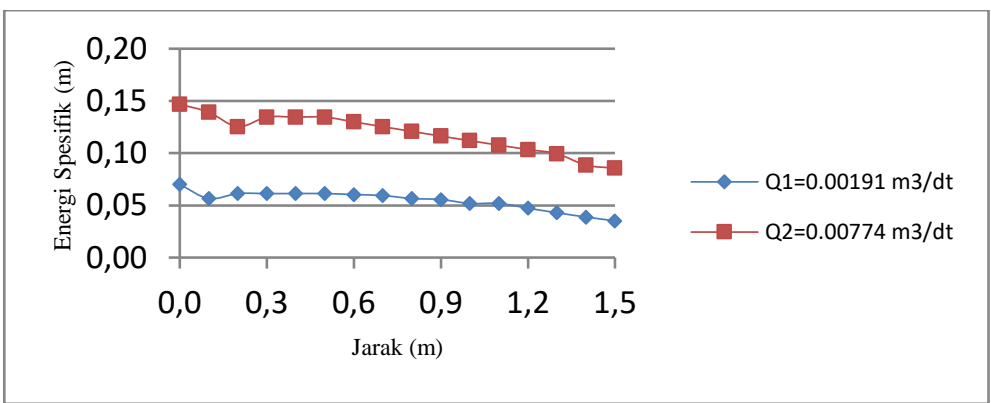

Gambar 7. Profil energi spesifik di hilir pintu air pada formasi paralel penuh $\mathrm{t}=12 \mathrm{~cm}$

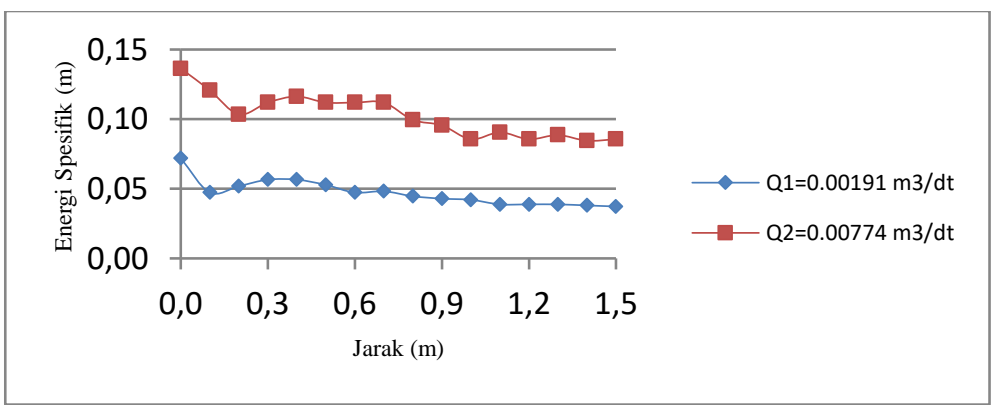

Gambar 8. Profil energi spesifik di hilir pintu air pada formasi paralel $1 / 2$ hulu $t=12 \mathrm{~cm}$ 


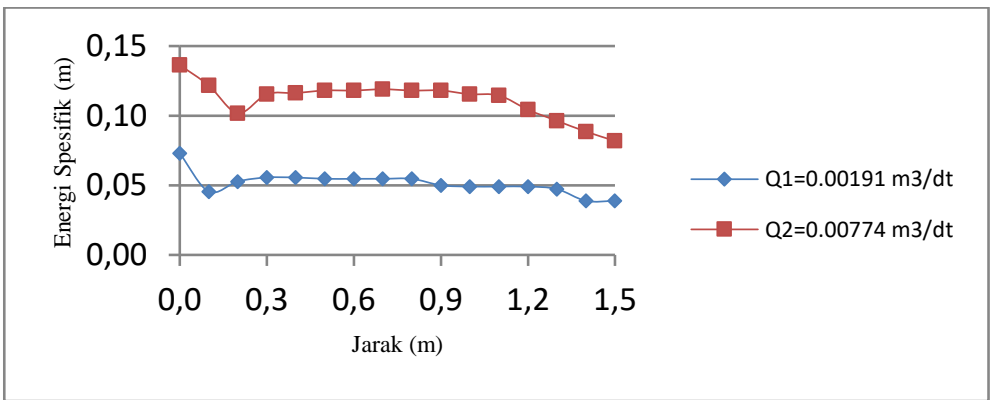

Gambar 9. Profil energi spesifik di hilir pintu air pada formasi paralel $1 / 2$ hilir $\mathrm{t}=12 \mathrm{~cm}$

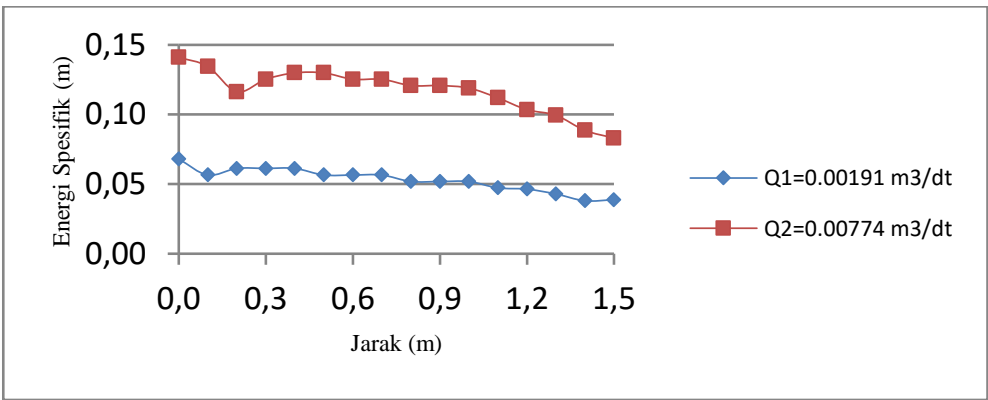

Gambar 10. Profil energi spesifik di hilir pintu air pada formasi paralel kombinasi I $\mathrm{t}=7 \mathrm{~cm} ; \mathrm{t}=12 \mathrm{~cm}$

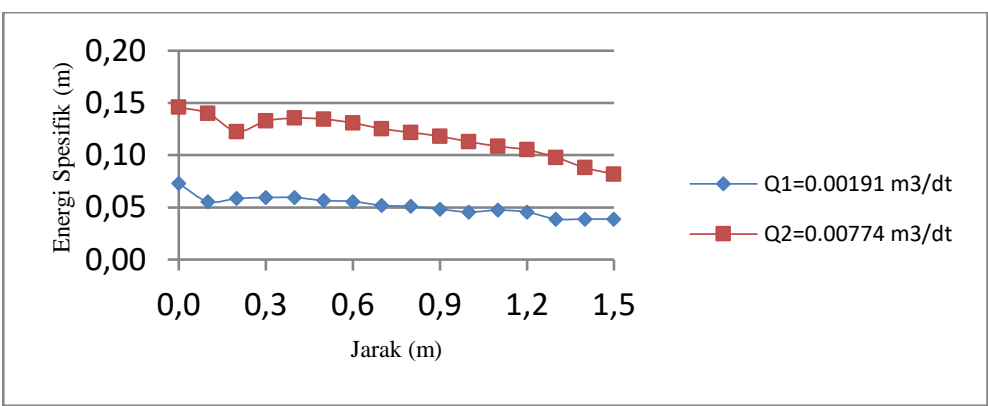

Gambar 11. Profil energi spesifik di hilir pintu air pada formasi paralel kombinasi II $\mathrm{t}=12 \mathrm{~cm} ; \mathrm{t}=7 \mathrm{~cm}$

Berdasarkan perbandingan antara Gambar 2 dan Gambar 4 sampai dengan Gambar 11, secara umum dapat dilihat beberapa hal sebagai berikut:

(i) semakin besar debit maka profil energi spesifik semakin besar, hal ini sejalan dengan hasil penelitian yang dilakukan oleh Aribawa (2018);

(ii) terdapat perbedaan profil energi spesifik antara sebelum dan sesudah pemasangan formasi model tiang;

(iii) setelah pemasangan formasi model tiang, baik pada debit $\mathrm{Q}_{1}$ maupun $\mathrm{Q}_{2}$, besarnya energi spesifik pada tiap-tiap titik pengukuran meningkat; apabila peningkatan energi spesifik tersebut dipengaruhi oleh peningkatan kedalaman aliran dan mempunyai efek pembendungan terhadap aliran maka hasil penelitian ini sejalan dengan hasil penelitian Harianja dan Gunawan (2007).

Apabila dilihat besarnya energi spesifik maksimum mulai dari Gambar 4 sampai dengan Gambar 11, maka dapat dijelaskan sebagai berikut: 
(i) Gambar 4, pada formasi paralel penuh $\mathrm{t}=7 \mathrm{~cm}$, energi spesifik maksimum pada debit $\mathrm{Q}_{2}$ sebesar $0,136 \mathrm{~m}$ yang terjadi pada jarak $0 \mathrm{~m}$ dari pintu air;

(ii) Gambar 5, pada formasi paralel $1 / 2$ hulu $\mathrm{t}=7 \mathrm{~cm}$, energi spesifik maksimum pada debit $\mathrm{Q}_{2}$ sebesar $0,132 \mathrm{~m}$ yang terjadi pada jarak $0 \mathrm{~m}$ dari pintu air;

(iii) Gambar 6, pada formasi paralel $1 / 2$ hilir $\mathrm{t}=7 \mathrm{~cm}$, energi spesifik maksimum pada debit $\mathrm{Q}_{2}$ sebesar $0,136 \mathrm{~m}$ yang terjadi pada jarak $0 \mathrm{~m}$ dari pintu air;

(iv) Gambar 7, pada formasi paralel penuh $\mathrm{t}=12 \mathrm{~cm}$, energi spesifik maksimum pada debit $\mathrm{Q}_{2}$ sebesar $0,147 \mathrm{~m}$ yang terjadi pada jarak $0 \mathrm{~m}$ dari pintu air;

(v) Gambar 8, pada formasi paralel $1 / 2$ hulu $t=12 \mathrm{~cm}$, energi spesifik maksimum pada debit $\mathrm{Q}_{2}$ sebesar 0,136 $\mathrm{m}$ yang terjadi pada jarak 1,4 $\mathrm{m}$ jarak $0 \mathrm{~m}$ dari pintu air;

(vi) Gambar 9, pada formasi paralel $1 / 2$ hilir $\mathrm{t}=12 \mathrm{~cm}$, energi spesifik maksimum pada debit $\mathrm{Q}_{2}$ sebesar $0,136 \mathrm{~m}$ yang terjadi pada jarak $0 \mathrm{~m}$ dari pintu air;

(vii) Gambar 10, pada formasi paralel kombinasi $\mathrm{I} \mathrm{t}=7 \mathrm{~cm} ; \mathrm{t}=12 \mathrm{~cm}$, energi spesifik maksimum pada debit $\mathrm{Q}_{2}$ sebesar $0,141 \mathrm{~m}$ yang terjadi pada jarak 0 $\mathrm{m}$ dari pintu air;

(viii) Gambar 11, pada formasi paralel kombinasi II t=12 cm; t=7 cm, energi spesifik maksimum pada debit $\mathrm{Q}_{2}$ sebesar $0,146 \mathrm{~m}$ yang terjadi pada jarak 0 m dari pintu air.

Berdasarkan uraian di atas, dapat dilihat bahwa perubahan energi spesifik terbesar terjadi pada formasi model tiang paralel penuh dengan $\mathrm{t}=12 \mathrm{~cm}$ (bandingkan antara Gambar 2, energi spesifik maksimum sebesar 0,132 m dan Gambar 7, energi spesifik maksimum sebesar 0,147 m).

\section{PENUTUP}

\section{Kesimpulan}

1. Sebelum pemasangan formasi model tiang di hilir pintu air, energi spesifik maksimum sebesar $0,132 \mathrm{~m}$ yang terjadi pada jarak $0 \mathrm{~m}$ di pintu air.

2. Pada pemasangan tiap-tiap formasi model tiang di hilir pintu air, energi spesifik maksimum yang terjadi lebih besar dibandingkan dengan energi spesifik maksimum sebelum pemasangan formasi model tiang.

3. Diantara delapan formasi model tiang, pada formasi model tiang paralel penuh dengan tinggi model tiang $12 \mathrm{~cm}$ terjadi energi spesifik maksimum terbesar. Besarnya energi spesifik yang dimaksud itu 0,147 m yang terjadi pada jarak 0 m di pintu air.

\section{Saran}

Dalam penelitian ini, model tiang dibuat kaku (rigid). Untuk penelitian selanjutnya, perlu dilakukan uji coba formasi model tiang dengan menggunakan model tiang yang tidak kaku (fleksibel).

\section{DAFTAR PUSTAKA}

1. Adipura, P. J. 2013. Pengaruh Variasi Kemiringan Tubuh Hilir Bendung dan Penempatan Baffle Blocks pada Kolam Olak Tipe Solid Roller Bucket terhadap Loncatan Hidrolis dan Peredaman Energi. 
https://core.ac.uk/download/pdf/148599844.pdf). (diakses 25 Februari pukul $08.30 \mathrm{WIB})$.

2. Aji, I. S., Maraden, S. 2008. Loncatan Air pada Saluran Miring Terbuka dengan Variasi Panjang Kolam Olakan. (http://www.ejurnal.ukrimuniversity.ac.id/file/11301.pdf). (diakses 27 Februari pukul 09.55 WIB).

3. Anggrahaini. 1997. Hidrolika Saluran Terbuka. Surabaya: CV Citra Media.

4. Aribawa, F.S. 2018. 30 Desember 2019. Pengaruh Kehilangan Energi Akibat Saluran Terbuka dalam Media Prototipe dengan Kemiringan Bersudut Studi Lapangan di Saluran Irigasi Dam Bago di Kecamatan Balung Desa Mlokorejo. Undergraduate Thesis. Universitas Muhammadiyah Jember. (http://repository.unmuhjember.ac.id/id/eprint/3211). (diakses 10 Desember 2020, pukul 16.30 WIB).

5. Bahar, T. P., Ruzardi. 2019. Studi Pengaruh Konfigurasi Baffle Blocks terhadap Peredaman Energi pada Konstruksi Bendung. (https://dspace.uii.ac.id/bitstream/handle/123456789/20039). (diakses 26 Februari pukul 17.30 WIB).

6. Chow, V. T. 1989. Hidrolika Saluran Terbuka. Jakarta: Erlangga.

7. Harianja, J. A., \& Gunawan, S. (2007). Tinjauan Energi Spesifik Akibat Penyempitan Pada Saluran Terbuka. Jurusan Teknik Sipil Fakultas Teknik UKRIM Yogyakarta. Majalah Ilmiah UKRIM Edisi, 1, 30-46. (https://www.academia.edu/download/54644863/ejurnal_aplikasi_saluran_terbuka.pdf). (diakses 26 Februari pukul 18.00 WIB).

8. Kamiana, I. M. 2018. Hidraulika; Teknik Perhitungan pada Aliran Terbuka dan Tertutup. Yogyakarta: Penerbit Teknosain.

9. Nenny, Imran, H. A. 2018. Studi Eksperimen Model Peredam Energi terhadap Loncatan Hidrolik pada Kolam Olakan. Jurnal Ilmiah Techno Entrepreneur Acta.

10. Setiawan, I., Suyanto, Solichin. 2013. Pengaruh Variasi Kemiringan pada Hulu Bendung dan Penggunaan Kolam Olak Tipe Slotted Roller Bucket Modification terhadap Loncatan Air dan Gerusan Setempat. e-Jurnal MATRIKS TEKNIK SIPIL.

11. Wulandari, A. 2020. Pemodelan Pengaruh Formasi Tiang Berbahan Kayu Galam Terhadap Kedalaman dan Kecepatan Aliran Di Hilir Pintu Air. Skripsi. Jurusan Teknik Sipil. Universitas Palangka Raya. 